\title{
Epilepsi EEG Verilerinin Makine Öğrenmesi Teknikleriyle Sinıflandırılması
}

\author{
Beyda Çağliyan ${ }^{1}$, Utku Köse $^{2^{*}}$ \\ ${ }^{1}$ Süleyman Demirel Üniversitesi, Fen Bilimleri Enstitüsü, Bilgisayar Müh. ABD., Isparta, Türkiye, (ORCID: 0000-0003-4952-8351), beydacagliyan@gmail.com \\ 2* Süleyman Demirel Üniversitesi, Mühendislik Fakültesi, Bilgisayar Müh. Bölümü, Isparta, Türkiye, (ORCID: 0000-0002-9652-6415), utkukose@,sdu.edu.tr
}

(İlk Geliş Tarihi 10 Ocak 2021 ve Kabul Tarihi 20 Mart 2021)

(DOI: $10.31590 /$ ejosat.857507)

ATIF/REFERENCE: Çağliyan, B. \& Köse, U. (2021). Epilepsi EEG Verilerinin Makine Öğrenmesi Teknikleriyle Sinıflandırılması. Avrupa Bilim ve Teknoloji Dergisi, (23), 163-172.

\section{Öz}

Teknolojinin geçmişe nazaran büyük bir hızla geliştiği günümüzde, çoğu alanda yazılımların, yapay zekâ tekniklerinin uygulama alanları artmış insanların işlerini kolaylaştırıcı bir özellik haline gelmiştir. Bu açıdan birçok alanda faaliyet gösteren makine öğrenmesi tekniklerinin sıklıkla rastlandığı problem alanlarından biri sağlık alanı olmuştur. Beynin davranışlarında rastlanan bozuklukların incelenmesinde ve modellenmesinde kullanılan EEG sinyalleri, dünya çapında birçok insanı etkileyen epilepsi hastalığının tanılanmasında temel bilgi kaynağı haline gelmiştir. Bu çalışma kapsamında da epilepsi hastalarından alınan EEG sinyalleri, 500 farklı kişi bilgisini içeren zaman serisi verisi olarak kullanılmıştır. Sınıflandırılan veri setinin bölümlendirme işlemi k-fold cross validation yöntemi ile ayrılmıştır. Epileptik nöbet tanılama sınıflandırma işlemi için kullanılan makine öğrenme tekniklerinden elde edilen sonuçların Yapay Sinir Ağı (YSA) \%76,39, Lineer Diskriminant Analiz (LDA) \%82,24, K-En Yakın Komşu Algoritması (K-NN) \%93,41 başarı elde ettiği görülmüştür (Bu çalışma Beyda Çağlıyan'ın Yüksek Lisans tezinden üretilmiştir).

\section{Epilepsy EEG Data Classification via Machine Learning Techniques}

\begin{abstract}
In today's world, where technology has developed rapidly compared to the past, the application area of software and artificial intelligence techniques in most areas has become a feature that facilitates the work of people. In this regard one of the problem areas where machine learning techniques operating in many fields are frequently encountered has been the field of health. EEG signals, which are used in the study and modeling of disorders in the brain's behavior, have become the main source of information in the diagnosis of epilepsy diseases that affect many people worldwide. In this study, EEG signals obtained from epilepsy patients were used as time series data containing 500 different person information. The segmentation operation of the classified data set is divided into with the k-fold cross validation method. The results obtained from the machine learning techniques used for the epileptic seizure diagnosis classification process were 76.39\% from the Artificial Neural Network (ANN), 82.24\% from the Linear Discriminant Analysis Algorithm (LDA), and $93.41 \%$ from the K-Nearest Neighbor Algorithm (K-NN) (This paper was produced by Beyda Çağllyan’s MSc. thesis).
\end{abstract}

Keywords: EEG Time Series, Epilepsy, Machine Learning, Neural Networks, K-Nearest Neighbor Algorithm, Linear Discriminant Analysis Algorithm, Classification.

\footnotetext{
* Sorumlu Yazar: Utku Köse utkukose@sdu.edu.tr
} 


\section{Giriş}

Halk arasında "Sara Hastalığı" olarak da bilinen Epilepsi, Dünya Sağlık Örgütü'nün (WHO) Nisan 2018'de yayınladığı "Epilepsi" raporuna göre; migren, felç ve alzheimer hastalıklarından sonra en çok görülen, Dünya çapında 50 milyondan daha çok kişide rastlanan bir hastalıktır (Musumeci, Bonaccorso \& Puglisi, 2019). Epilepsi, beyinde yer alan sinir hücrelerinin normalden farklı şekilde elektrokimyasal boşalma yapmasıyla gelişen nörolojik bir rahatsızlıktır (Sanei \& Chambers, 2007). Bu rahatsızlığın ana nedeni henüz tam olarak bilinemese de epilepsiye başlıca; doğum öncesi veya doğum anında oluşan beyin hasarları, düşük doğum ağırlığı, genetik faktörler, kafa travmaları, menenjit gibi beyin enfeksiyonu, beyne giden oksijen miktarını engelleyen inme gibi durumlar etki etmektedir ("World Health Organization", 2020). Epilepsi rahatsızlığı geçiren hastaların \%30'luk kesiminde ilaçlar etki etmemekte bu sebepten her üç epilepsili hastadan birine ilaç tedavisi veya cerrahi herhangi bir operasyon uygulanamamaktadır. Böylece hastalar, ne zaman açığa çıkacağı kestirilemeyen ve önlenemeyen kriz tehlikesiye karşılaşmak durumunda kalmaktadırlar (Özcan, 2020).

Epileptik sinyallerin tanılanması, çeşitli sinir sistemi hastalıklarının arkasında yatan sebeplerin aydınlatılması ve beynin işleyiş yapısının araştırılması adına Elektroensefalografi (EEG) sinyalleri kullanılmaktadır. EEG sinyallerindeki dik darbeler uzman sağlık çalışanları tarafından gözlemlenip yorumlanmaktadır (Kaya \& Türk, 2017). EEG sinyalleri beyin hareketlerinin incelenmesi ve modelinin çıkarılması bakımından önemli bir role sahiptir. Beynin farklı uyaranlara verdiği tepkilerin zaman veya frekans düzleminde içeriklerine göre araştırma yapılabilmesini sağlayan önemli bir konudur. Beyinde duyu ve motor alanların tespit edilebilmesi için EEG oldukça katkı sağlamaktadır. Herhangi bir sarsıntı türü yaralanma, tümör vb. gibi durumların ardından oluşan beyin hasarlarının konumunun tespitinde EEG kullanılırken; bu hasar gören alanlarda sinyal alınamayan sessiz veya beklenmedik şekilde sinyal veren dalgalanmaları k1yaslayabilmektedir (Pehlivan, 1997).

EEG, beynin davranışlarının elektriksel olarak kayıt altına alınması işlemi olup uluslararası alanda onaylanmış, standartlaştırılmış haritalandırma işlemine uyarak belirli şartlar altında, dijital ortamda ya da kâğıt üzerine yazdırma şeklinde yapılır. EEG kayıtlama işlemi için standardı belirlenmiş çalışmalarda, kafa derisi üzerine ve kulak memelerine yerleştirilen elektrotlardan alınan sinyaller; uyku hali ya da uyanıkken, çeşitli göz hareketlerinin kaydedilmesi sonucu elde edilir.

İleri teknoloji imkânları, mühendislik alanında, endüstriyel alanda, bilgi işlemede, askeri alanda, modellemede, tıbbi alanda, görüntü işleme, tanılama işlemlerinde, biyomedikal uygulama alanlarında olduğu gibi farklı alanlarda kullanılmaktadır (Sağıroğlu, Güney \& Erler, 2003). Çeşitli hastalıklara tanı konulma şekilleri gelişme göstermekle beraber artık belirli cihazlarla alınan verilerin kolay yoldan yorumlanması için de bazı teknikler kullanılmaktadır (Albayrak, 2008). Yapay zekâ teknikleri çoğunlukla bu amaçla kullanılan yöntemlerin başında gelmektedir. Bu tekniklerden biri olan sinir ağları teknikleri gibi makine öğrenmesi teknikleri de beynin faaliyeti sırasında elektriksel potansiyelin kaydedilmesini sağlayan EEG sinyallerinin analizinde kullanılmaktadır ve bilgisayarın öğrenmesi için zemin sağlamaktadır (Alkan, Subaşı \& Kıymık, 2003).

Beynin çeşitli bozukluk durumlarında kaydedilmiş olan EEG sinyallerinin belirli zaman aralıklarında gösterdiği değişikler anlamlandırılabilir olmaktadır. Böylece EEG sinyallerinin zaman serisi olarak modellenip biçimlendirilmesi, bu sinyaller üzerinde daha rahat öngörüde bulunma, verilerin sınıflandırılması gibi işlemleri yapılabilmesi imkânını vermiştir (Şenol, 2006).

\section{Materyal ve Metot}

\subsection{Epilepsi}

Epilepsi, kortikal nöronlardaki üst düzey elektriksel deşarj olma sonrasında açığa çıkan ani, tekrarlayan, tanımlanabilir bir durumla tetiklenmemiş epilepsi nöbetleri ile karakterize olmuş bir bozukluk durumudur (Akdağ, Algın \& Erdinç, 2016). Epilepsi, beynin normal aktivitesinin, sinir hücrelerinde kalıcı olmayan surette açığa çıkan normal olmayan elektriksel aktivitesi sonucunda hasar görmesi ile meydana gelen bir rahatsılıktır. Halk arasında epilepsi hastalığı, "Sara Hastalığı" veya "Tutarık" olarak da anılmaktadır. Epileptik nöbeti (kriz) gerçekleştiği anda hasta bireyde geçici bilinç kaybı veya farklı belirtiler ortaya çıkmaktadır ("Yeditepe", 2019). Vücudun belli bir kısmını (kısmi) veya tüm vücudu etkisi altına alan istemsiz hareketlerin ortaya çıktığı, bağırsak veya mesane gibi organların kontrolünün kaybına neden olan bir rahatsızlıktır ("World Health Organization", 2020). Nöbet geçirme durumu, epilepsisi olan hastanın rahatsızlığının anlaşılmasının bir yoludur.

Epilepsi dünya çapında 50 milyona yakın kişiyi etkileyen, tekrarlayan (kronik), bulaşıcılığı olmayan sık karşılaşılan bir hastalıklardan bir tanesidir ("World Health Organization", 2020). Ülkemizde ise bu hastalığın görülme oranı, tıpkı dünyada da olduğu gibi $\% 0,5$ - \%1 arasında bir oranda olup bu say1 Türkiye'de yaklaşık olarak sekiz yüz bindir ve bunların dört yüz binden daha fazlasını yetişkinler dışında çocuklar oluşturmaktadır. Günümüzde kadınlarla erkekler arasında hastalık ile karşılaşılma oranı arasında büyük bir fark yoktur ve her yaştan, milletten, etnik gruptan ve sosyoekonomik statüden kişilerin epilepsili yaşamını sürdüğü görülmektedir (“S.B.Ü.”, 2020).

Epilepsi, yaklaşık olarak M.Ö. 4000 senelerinde yazılı kayıtlarda yer alan insanlık tarihinin bilinen en eski hastalıklarından biridir ("World Health Organization", 2020). Çocukluk dönemlerinde ve yetişkinlikte maksimum seviyede iken genç yetişkinlikte daha hafif seviyededir (Zupec-Kania ve Spellman, 2009). Bu hastalığın özelliği belirgin bir yaşta açığa çıkmamasıdır. Epilepsiye, herhangi bir yaşta rastlanabilmekte fakat çocuklarda 16 yaşına kadar ve yetişkinlerde 65 yaşın üstünde rastlanma olasılığı artmaktadır ("Yeditepe", 2019).

Epilepsi tamamıyla iyileşebilen bir rahatsızlık değil iken doğru ilaçların kullanımı sonucunda hasta bireylerin bir kısmı nöbet geçirmeden yaşamlarını sürdürülebilmektedir. Çok sık olmasa da beyindeki epileptik bölge ameliyat yardımıyla devre dışı bırakılabilir veya tamamen yok edilebilir. Zihinsel bir eksiklik durumu ile epilepsi rahatsızlığı paralellik gösterdiği görülmemiştir. Fakat zihinsel noksanlıkları olan bireylerde epilepsi hastalığına yakalanma olasılıkları normal işlevlere sahip zihinlere nazaran daha da artmaktadır (Albayrak, 2008). 


\subsection{Elektroensefalografi}

Elektroensefalografi (EEG), kafatasına konumandırılan elektrotlar yardımıyla beynin davranışları sırasında kendisinin ürettiği, sürekli ve ritmik elektriksel hareketlerinin değişiminin incelenmesinde, uygun yazdırma sistemleri aracılığıyla kâğıt üzerine sayısal bir veri olarak işleyerek kayda alınan, genel olarak geçirilen nöbetlerin değerlendirilmesi için kullanılan ve tanı koymayı sağlayan tekniktir. Fiziksel olarak bütünüyle periyodik olmayan fakat ritmik olarak tanımlanan potansiyel sinyallerin frekansları, beynin hareket durumuna bağlı olarak, 0,5-70 Hz aralığında ve genlikleri $5-400 \mu \mathrm{V}$ aralığında farklılık gösterir (Şenol, 2006).

EEG çekme işlemi için, elektrotlar saçlı kafa derisine iletken bir madde olan pasta aracılığıyla konumlandırılması yapılır. Olası değişimler bilgisayara kaydedilerek ortaya çıkan sonuçlar yorumlanır. EEG için elektrot konumlandırma işlemi, 1958'de Uluslararası Federasyon vasıtasıyla kabul edilmiş olan "10-20" sistemi olarak tanımlanmış kafatası çevresindeki 21 elektrot bölgesini bünyesinde barındıran elektrot konumlandırma şekli olarak standart haline getirilmiştir. $\mathrm{Bu}$ standartlaştırma durumu, Şekil 1 ve 2'de görüldüğü gibidir. EEG araçları beynin arklı alanlarının faaliyetlerini aynı anda kaydedebilmek için çoğunlukla 8 ya da 16 kanallı olarak yapılmaktadır (Pehlivan, 1997).

\section{Electroencephalogram (EEG)}

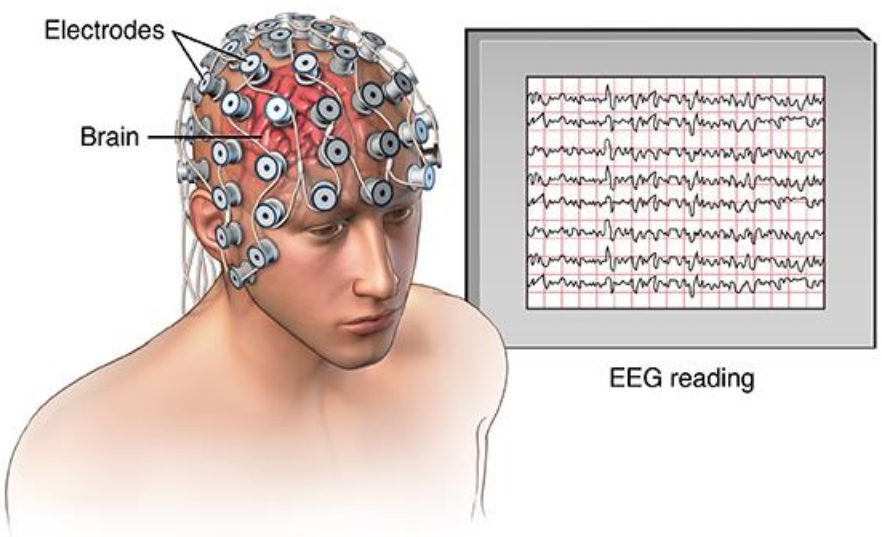

Şekil 1. Uluslararası standartlarda Elektroensefalografi (EEG) kayıtlama işlemi (Köse, 2018a).

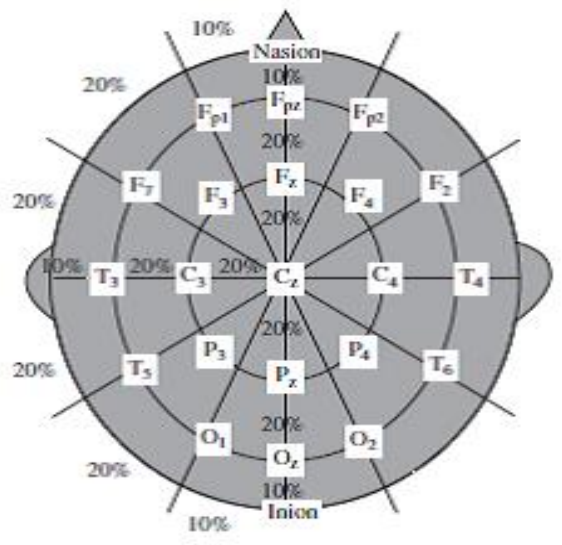

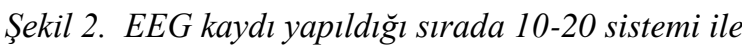
standardize edilmiş elektrot yerleştirilmesi pozisyonu (Taywade \& Raut, 2012).
- $\quad$ F: Ön kisım lobları,

- T: Şakağa ait loblar,

- C: Merkezi (orta) loblar,

- P: Parietal (kafatası yanı kemiği) loblar,

- O: Oksipital (kafatasının arka kısmına ait) lobları ifade etmektedir.

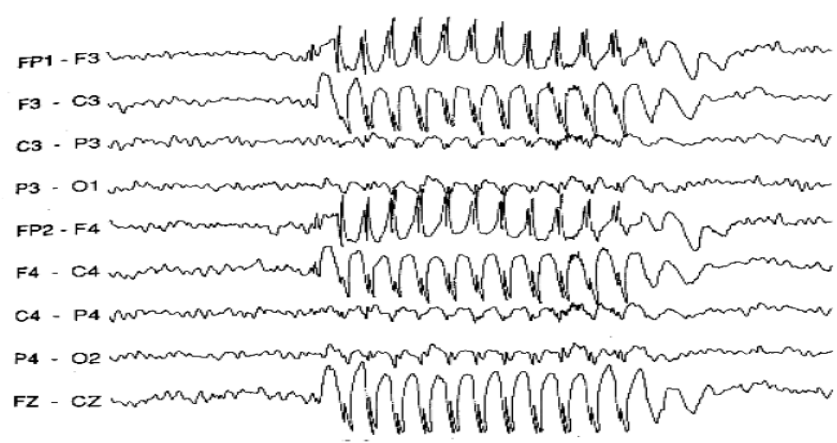

$r_{\text {SEC. }} I 200 \mu \mathrm{V}$

Şekil 3. Epileptik nöbet sırasında çekilmiş örnek EEG kaydı (Özer, 2015).

Şekil 3'te belli zaman aralığında EEG sinyalinin epilepsi nöbeti geçirimi sırasında rastlanan değişiklikler görülmektedir. Genel olarak karşılaşıldığı gibi, $3 \mathrm{~Hz}$ frekansında diken şeklinde dalgalanan sinyal aniden ortaya çıar ve birkaç saniye devam edip kaybolur (Özer, 2015).

EEG'de ölçülen potansiyel, beyinde meydana gelen sinir hücrelerinin (nöronların) aktivitelerinin toplamıdır. Gerçekleşen bu potansiyelin kafatası dişında bile ölçülebilir durumda olması için, nöronların aynı yüzey üzerinde paralel şekilde yerleşmiş durumda olmaları gerekmektedir (Varsavsky, Mareels \& Cook, 2016; Özcan, 2020).

EEG, alınan sinyalin epileptik özellikte mi değil mi, epilepsinin hangi çeşidi olduğu, epileptik olmayan bir durumda tedavi uygulanmasının etkisinin ne olacağı, epileptik bir durumda tedavi uygulanmasının sonucu durdurulabilir mi gibi sorulara yanıt almak için kullanılır.

\subsection{Yapay Sinir Ağları}

Yapay sinir ağları (YSA) ile ilgili ilk çalışma 1943 yılında Nörofiyolojist Waren Mc. Culloch ile matematik bilimcisi Walter Pitts tarafinca yayımladıkları makalelerinde elektrik devrelerinden basit bir yapıda sinir ağları tasarladıklarından bahsetmeleriyle başlamış ilerleyen zamanda perception kavramının bulunması sonucu YSA yapısının gelişmesi sağlanmıştır. 80’lerin sonunda çok katmanlı sinir ağları için geri yayılımlı öğrenme algoritmasının geliştirilmesi ile günümüzdeki yapısını kazanmasına olanak sağlamıştır.

Beyinde yer alan sinir hücrelerinin çalışma şeklini taklit ederek oluşturulan YSA, birbirlerine sinaptik bağlara benzer yapılarda bağlanmış yapay sinir hücrelerinden oluşmaktadır. Her nöron arasındaki bağlantı sayesinde nörona gelen bilgi bir diğer nörona aktarılır (Alan, 2020).

YSA, insan beynin yapısını ve nöronları arasındaki bağlantılardan yararlanılarak geliştirilmişse de nöronların bağlandığı gerçek bir beyinden farklı olarak katmanlara, bağlantılara ve veri iletme yeteneklerine sahiptir. Başka bir 
değişle biyolojik sinir sistemi modelinin matematiksel olarak gösterime dönüştürülmüş hali olarak da ifade edilebilir (Gershenson, 2021). Bu sistemler, kendi kendilerine öğrenebilme özelliğine sahiptirler. Çoğunlukla problemin çözümünün veya tespitinin karmaşık olduğu uygulamalarda en iyi çalışma performansını sağlayabilmektedir ("Copeland", 2006).

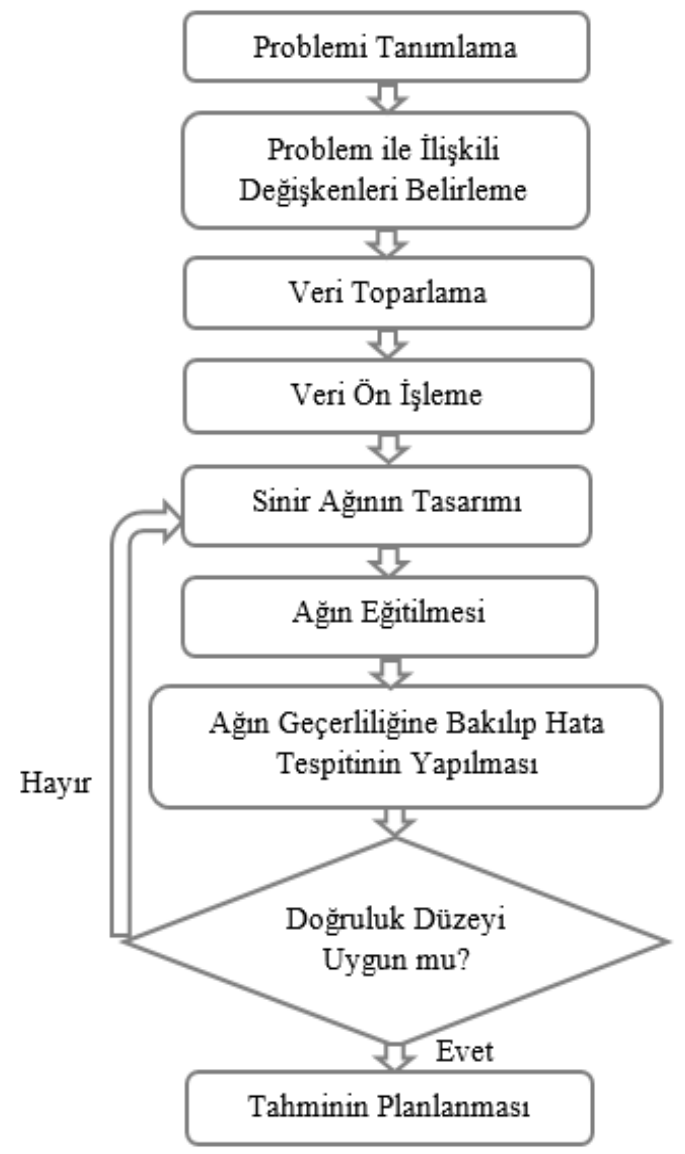

Şekil 4. YSA tahmin yöntemi (Hu, 2002).

Bir sinir ağı tecrübelerden faydalanarak bilgi depolamak ve verileri kullanılacak düzeye getirmek için doğal bir eğilimi olan basit işlem öğelerinden oluşan paralel şekilde dağıtılmış bir işlemcidir (Haykin, 1999). Bu yönüyle sinir ağları belki de insan düşünce ve öğrenme süreçlerine dair en anlamlı makine öğrenmesi tekniklerinden biri olmakta, yine insan odaklı farklı problem çözümlemeleriyle birlikte özellikle felsefi açıdan yapay zekâ çözümlerinin tartışılması noktasında bilimsel literatürde çok yönlü yansımalar oluşturmuştur (Boz \& Köse, 2018; Cevizoğlu, 2019; Deperlioğlu, 2018; Hasson, Nastase \& Goldstein, 2020; Köse, 2018b; Yegnanarayana, 2009).

YSA, insan beyninin öğrenme işlevi örnek alınarak tasarlanan hücrelerden meydana gelmektedir (Asilkan ve Irmak, 2009). YSA'da insanlarda bulunan biyolojik sinir hücresindeki nöronlara benzer yapılar yer almaktadır. Yapay sinir hücresini meydana getiren bu yapıların bir araya gelerek yarattığ yapay sinir ağıdır (Graupe, 2013).

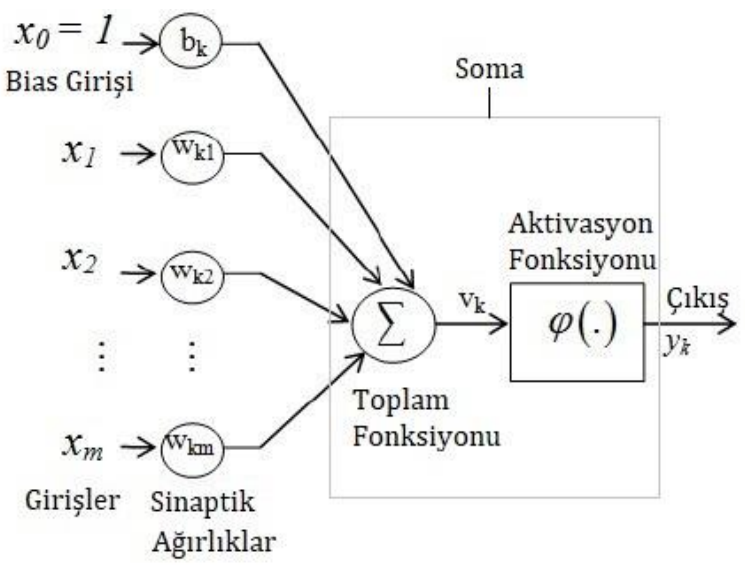

Şekil 5. Tek Katmanlı YSA (Haykin, 1999).

Bir yapay sinir hücresinde girdiler $\left(\mathrm{X}_{1}, \mathrm{X}_{2}, \ldots . ., \mathrm{X}_{\mathrm{m}}\right)$, kendilerine ait olan $\left(\mathrm{w}_{\mathrm{k} 1} \mathrm{w}_{\mathrm{k} 2}, \ldots \ldots, \mathrm{w}_{\mathrm{km}}\right)$ ağırlıkları ile çarpıldıktan sonra ve dışarıdan bir bias değerinin $\left(b_{k}\right)$ uygulanarak toplam fonksiyonu ile birleştirilip bir aktivasyon fonksiyonuna gönderilirler. Aktivasyon (transfer) fonksiyonuna iletilen bu sinyal, bu noktada artık işlenerek çıktıya (Y) dönüştürülür (1) (2) (Öztemel, 2012).

$u_{k}=\sum_{J=1}^{m} w_{k j} \cdot x_{j}$

$y_{k}=\Psi\left(v_{k}+b_{k}\right)$

Çıkış durumunda olan Y değerinin hesaplanmasında X değeri ile girdileri, $\mathrm{W}$ değeri ile ise her bir girdinin kendi pozitif, negatif ya da sıfır değerini alabilen ağırlıklarını yani sinir hücresine gelen bilginin önemi ifade edilmektedir. $v_{k}$ değeri bir dış girdi olan bias değerinin $\left(b_{k}\right), \Psi$ aktivasyon fonksiyonu ile işlemden geçirilip $y_{k}$ çıktısının elde edilişi ifade edilmiştir. Burada aktivasyon fonksiyonu $y_{k}$ çıkış değerini kontrol ederek hücrenin aktif olup olmama durumuna karar vermeyi sağlar.

\subsection{Lineer Diskriminant Analiz}

Lineer Diskriminant Analiz (LDA) algoritması, 1936 yılında ikili sınıflandırma problemlerinin çözümü için R. A. Fisher tarafınca geliştirilmiş sonrasında C. R. Rao tarafından ikiden çok sınıflandırma durumu içeren problemlerin çözümü için formülüze edilmiş basit bir yapısı olmasına rağmen karmaşık problemlerde olumlu sonuçlar veren bir algoritmadır.

LDA, birden çok özelliği barındıran denetimli öğrenme makine öğrenme problem durumlarında sınıflandırma işleminde lineer kombinasyonların birbirinden ayırılması için kullanılan ve sınıfların her biri arasındaki varyans değerlerinin maksimum seviyeye getirilmesini hedefleyen tekniktir. Ayrıca bu teknik, veri setindeki sınıflar arasında bir karar alanı oluşturarak verilerin dağglım işlemini daha anlaşılır bir şekle getirmeye çalışır (Başçıl, 2015).

İki sınıf bulunduran problemler durumları için LDA'nın formülü için $y(x)$ lineer diskriminant fonksiyonu, $A$ ve $B$ sınıfları, $x$ giriş vektörünü, $w$ özellik vektörünün sahip olduğu ağırlığ $1, w_{0}$ bias değerini (eşik değeri) ifade ederken $C$ ise sınıflandırma işlemini temsil etmektedir (3) (4).

$y(x)=w^{t} x+w_{0}$ 
$C=\left\{\begin{array}{l}\text { Ĕger } y(x)>0, x \in A \\ \text { Ĕger } y(x)<0, x \in B\end{array}\right.$

$\frac{w^{t} x}{|w|}=-\frac{w_{0}}{|w|}$

$\mathrm{y}(\mathrm{x})$ lineer diskriminant fonksiyonunun 0 olması hali karar bölgesi anlamına gelmektedir ve bölge sınırı formülü Denklem 5'de olduğu gibidir.

İki sınıfı bulunan problemler için LDA karar bölgesinin gösterimi Şekil 6'da gösterilmiştir.

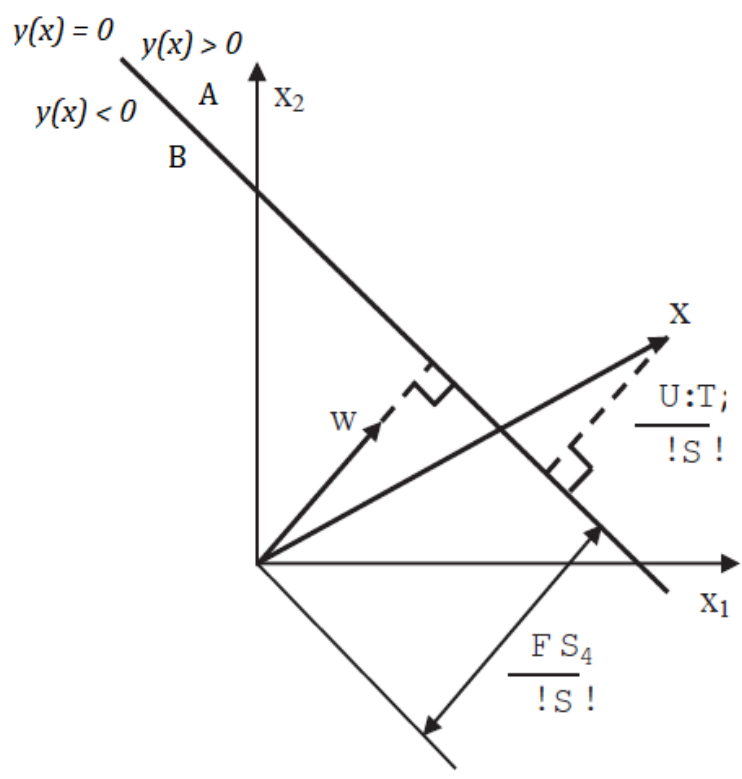

Şekil 6. İki sınıfa sahip problem durumları için LDA karar bölgesi (Başçıl, 2015).

\subsection{K-En Yakın Komşu Algoritması}

K-en yakın komşu algoritması (K-NN), sınıflandırma çalışmalarında sıklıkla kullanılan denetimli öğrenme teknikleri arasında bulunmaktadır. K-NN, sinıflandirılması istenen bir öğrenme veri kümesinin belli bir komşu sayısı yakınlığ aracılığıyla sınıflandırma yapması temeline dayalı olarak çalışan bir algoritmadır. Komşu sayısı k ile gösterilirken sınıflandırma yapılacak veriye olan yakınlığı önem arz ettiği için k-en yakın komşu algoritması adı verilmiştir.

Karmaşık bir yapısı olmayan K-NN, rekabetçi sonuçlar verir ve kimi durumlarda daha karmaşık öğrenme tekniklerine göre daha iyi performans sergileyebilmektedir (Kaya, 2019). Bu teknik, diğer yöntemlerle kıyasla az sayıda sınıfa sahip olan durumlar için daha basit fakat daha etkili bir öğrenme yöntemi sunar (Eşme \& Karlik, 2014).

K-NN, uzaklığı temele alan örnek tabanlı bir öğrenme algoritması olması sebebiyle, algoritma karşılaştığı her yeni bir veri örneğine rastladığında yeni veride yer alan tüm örneklerde olan mesafeler hesaplanır. Bu hesaplama ardından sinıf etiketleri daha öncesinden bilinen veri örneklerinden $\mathrm{k}$ adet en yakın komşusunu bularak yeni karşılaşılan örnekte eğitim verisinde olan örneklerle kıyas edilip aralarındaki benzerliklere bakılarak sınıflandırma yapılır (Mitchell, 1997). Benzerlik ölçütü mesafeyi temele aldığ örneklerin daha çok benzer olduğunu gösterir ve benzer grupta olmalıdır denir (Panjeh, 2018).

Yeni veri örneği k en yakın komşunun çoğunluğunda olduğu belli bir sınıfa atanır. Örneğin, $\mathrm{k}=1$ seçilmişse sınıflandırılmaya çalışılan yeni veri örneği en yakında olan 1 komşusunun var olduğu sınıfa atanırken $\mathrm{k}=3$ seçilmişse, sınıflandırılmaya çalışılan yeni veri için en yakında olan 3 komşusu baz alınarak sınıfa atanır. Şekil 7'de k=3 olarak düşünüldüğü durumda yeni gelen örneğin sinıflandırılması durumu görülmektedir. Burada d1, d2, d3 karşılaşılan yeni verinin sınıflardaki verilere olan en yakın 3 komşusuna olan mesafe değerleridir. $\mathrm{Bu}$ işlem sonrasında en yakın komşulukta ikisinin Yıldız Sınıfı'na daha yakın olmasından dolayı veri Yıldız Sınıfı'na atanır (Polat, 2016).

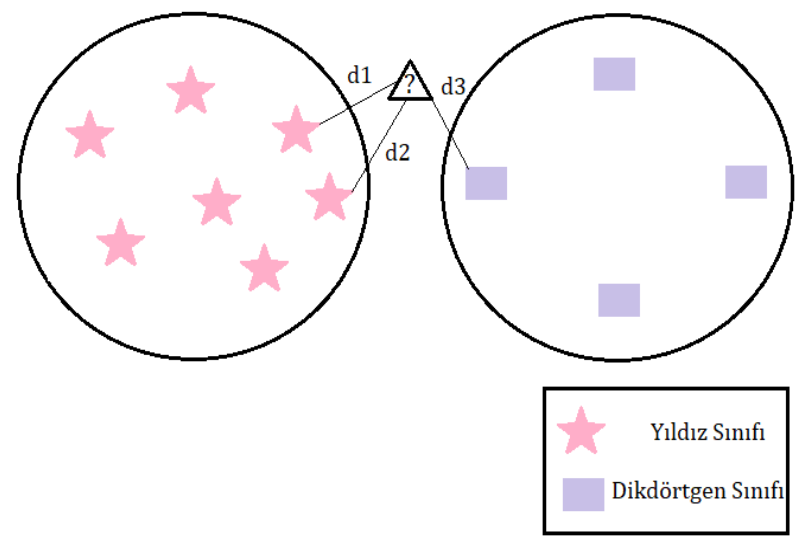

Şekil 7. $k=3$ için $K-N N$ sınıflandırması

K-NN algoritmasının çalışma performansını büyük ölçüde etkileyen girdi parametrelerden biri olan örnekler arasındaki uzaklığın ölçülme şeklidir. Literatürde incelendiğinde sıklıkla denenen uzaklık hesaplama teknikleri Öklid Uzaklığı ve Minkowski Uzaklığı teknikleridir.

- Minkowski Uzakliğl (Minkowski Disatnce), Öklid boyutunda tanımlı olan bir dizi şeklidir. Veri madenciliği uygulamalarında, sınıflama ve kümeleme gibi makine öğrenmesi uygulamalarında çoğunlukla denenen uzaklık hesaplama yöntemidir. Herhangi iki nokta olarak düşünülen A ile $B$ arasındaki Minkowski Uzaklığ $1, A=\left(x_{1}, x_{2}, \ldots, x_{n}\right)$ ve $\mathrm{B}=\left(\mathrm{y}_{1}, \mathrm{y}_{2}, \ldots, \mathrm{y}_{\mathrm{n}}\right)$ olmak üzere Denklem 6'da ifade edildiği şekilde hesaplanır (Taşçı \& Onan, 2016).

$\mathrm{d}=\left(\sum_{i=1}^{n}\left|x_{i}-y_{i}\right|^{p}\right)^{1 / 9}$

Minkowski uzaklığı, Denklem 6'da gösterildiği gibi belli bir formülle hesaplaniyor olup p'nin değerlerinin değişen kombinasyonları ile çeşitli uzaklık ölçme yöntemleri türetmek amacıyla da kullanılmaktadır. Örneğin p'nin değerinin 1 olduğu özel bir durum olan Manhattan Uzaklığını, p'nin değerinin 2 olduğu başka bir özel durum olan Öklid Uzaklığını ve $n \rightarrow \infty$ iken ki özel hali, Chebyschev Uzaklığının formülünü oluşturmaktadır (Taşçı \& Onan, 2016).

- Öklid Uzaklığl (Eculidean Distance), tıpkı Minkowski Uzaklığı gibi sınıflama ve kümeleme algoritmaları gibi makine öğrenmesi uygulamalarda sıklıkla denenen uzaklık 
ölçme yöntemidir. Öklid uzaklığı, belli iki nokta arasındaki doğrusal uzaklıktır ve herhangi iki nokta olan $A$ ve $B$ arasındaki Öklid Uzaklığ $1, A=\left(x_{1}, x_{2}, \ldots, x_{n}\right)$ ve $B=\left(y_{1}\right.$, $\left.\mathrm{y}_{2}, \ldots, \mathrm{y}_{\mathrm{n}}\right)$ olmak üzere Denklem 7'de ifade edildiği şekilde hesaplanır (Taşçı \& Onan, 2016).

$$
d=\sqrt{\sum_{i=1}^{n}\left(x_{i}-y_{i}\right)^{2}}
$$

Öklid uzaklığı, K-NN sınıflama algoritması ve K-ortalama kümeleme algoritması örneklerinde olduğu gibi sınıflama ve kümeleme algoritmalarında mesafe belirlemesi için kullanılan temel uzaklık ölçme yöntemidir.

Literatür incelendiğinde Minkowski uzaklık hesaplama yöntemlerinden türetilmiş olan Manhattan Uzaklığı, Chebyschev Uzaklığı gibi yöntemlerin yanı sıra kategorik öznitelik değerleri arası mesafe hesabını belirlemek için kullanılan Dilca Uzaklığı yöntemine de rastlanmıştır.

\subsection{Veri Seti}

Veri setinin ana hali olan EEG sinyalinin kaydedilme işlemi, Bonn Üniversitesi Epileptoloji Bölümü'nde yapılmıştır. Verilerin tümü 5 küme (A-B-C-D-E kümeleri) şeklinde oluşturulmuştur. Şekil 8'de bu kümelerin EEG sinyalleri gösterilmiştir. Gözleri açık sağlığı yerinde gönüllü kişilerden elde edilen veriler A kümesinde, gözleri kapalı olanlar kişilerden alınan veriler B kümesinde, C ve D kümelerinde ise sırasıyla, epilepsi hastası kişilerin kafataslarının farklı bölgelerinden alınan veriler, E kümesinde ise hasta bireylerin epilepsi nöbeti geçirdikleri anda alınan ölçümleri kaydedilmiştir. Her bir veri kümesi 23,6 saniyelik 100 tek kanallı EEG segmenti içermektedir. Segmentlerin tamamı artefaktları doğrudan gözle incelenerek, çok kanallı EEG kayıtlarından kesilerek seçilmiştir. EEG sinyalleri 12 bit analog sayısal dönüştürücü aracılığıyla dönüştürülüp makineye, verilerin örnekleme hızı 173,61 Hz frekansı (toplam 4097 tane) olarak aktarılmıştır. Epileptik özelliklerin kendini belli etme aralığı $30-40 \mathrm{~Hz}$ altında olması sebebiyle zaman serilerinin spektral bant genişliği $0,5 \mathrm{~Hz}$ ile 85 $\mathrm{Hz}$ aralığında olan sinyallere ve $0,53 \mathrm{~Hz}$ ile $40 \mathrm{~Hz}$ aralığında banda ait filtre uygulanmıştır (Andrzejak, Lehnertz, Rieke, Mormann, David \& Elger, 2001).

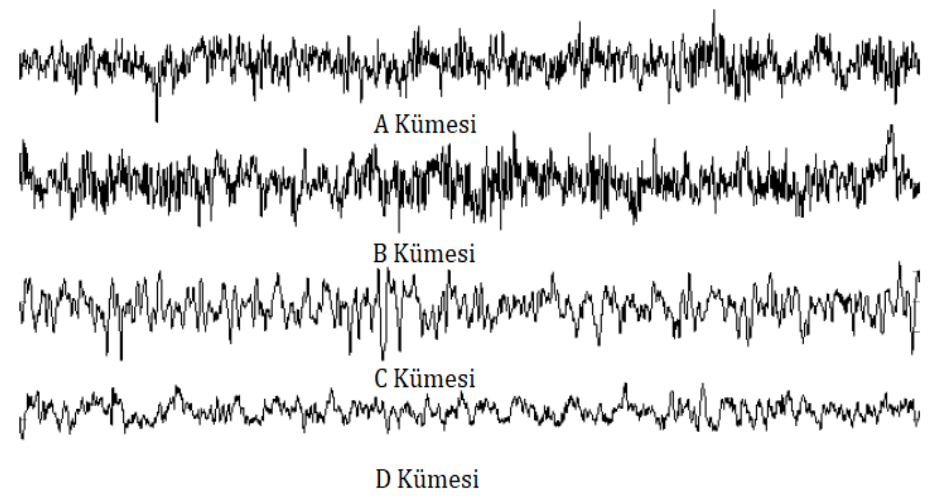

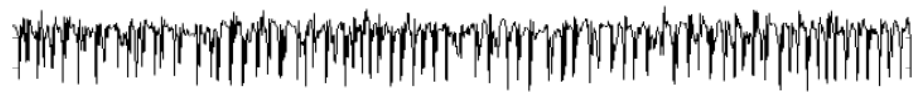
E Kümesi

Şekil 8. A, B, C, D, E kümelerinin örnek EEG sinyalleri (Tekin, Kaya \& Tağluk, 2011).
Çalışma kapsamında kullanılan veri seti düzenlenmiş zaman serisi verisi ise "Epileptik Nöbet Tanıma Veri Seti" adı altında kaydedilmiş olan UCI veri tabanından alınmıştır. Bu veri setinde 500 farklı kişi bilgisi, 4097 veri noktası 23 parçaya (chuck) bölünerek karıştırılmıştır. Her bir parça 1 saniye için 178 veri noktasından oluşmaktadır ve her veri noktası, zaman içerisindeki değişik bir noktadaki EEG kaydının değerini ifade etmektedir.

\section{Araştırma Sonuçları ve Tartışma}

\subsection{YSA Bulguları}

Çalışma için kullanılan epilepsi EEG veri setinde 178 özellik veri noktası YSA modeline girdi olarak verilmiştir. YSA'nın ara katman sayısı ile çıkış katman sayıları tek olarak belirlenmiştir. Tasarlanan YSA modelinin programdan alınan hali, Şekil 9'da görüldüğü gibidir.

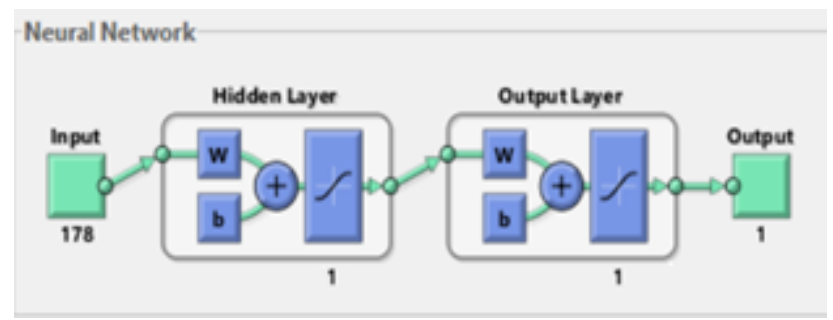

Şekil 9. Tasarlanan YSA modeli.

YSA'nın eğitimi için Trainlm yani Levenberg-Marquadty optimizasyonuna bağlı olarak ağırlık ve bias değerleri oluşturan teknik, hızlı bir eğitim algoritması olması sebebiyle kullanılmıştır. Sinir ağında verileri bölümlendirirken rastgele indeksler kullanarak 3 ayrı sete bölen dividerand algoritması yöntemi uygulanmıştır.

YSA'nın eğitim, doğrulama ve test verileri üzerindeki tahmin işlemi sonucu eğitim de $\% 77,09$, testte $\% 73,90$ ve totalde başarım değerinin \%76,39 olduğu görülmüştür. Bu sonuç Şekil 10 ve Şekil 11 'de olduğu gibidir.

Şekil 12'de YSA'dan ulaşılan tahmin edilen değerler ile gerçek veriler arasındaki ortalama hata karesi hesaplanmış grafikte; eğitim, doğrulama ve test verilerinin tahmininde en iyi sonuca \%85,31 ile 5. epoch adımında rastlandığı toplamda 1000 epochta elde edildiği gösterilmiştir.

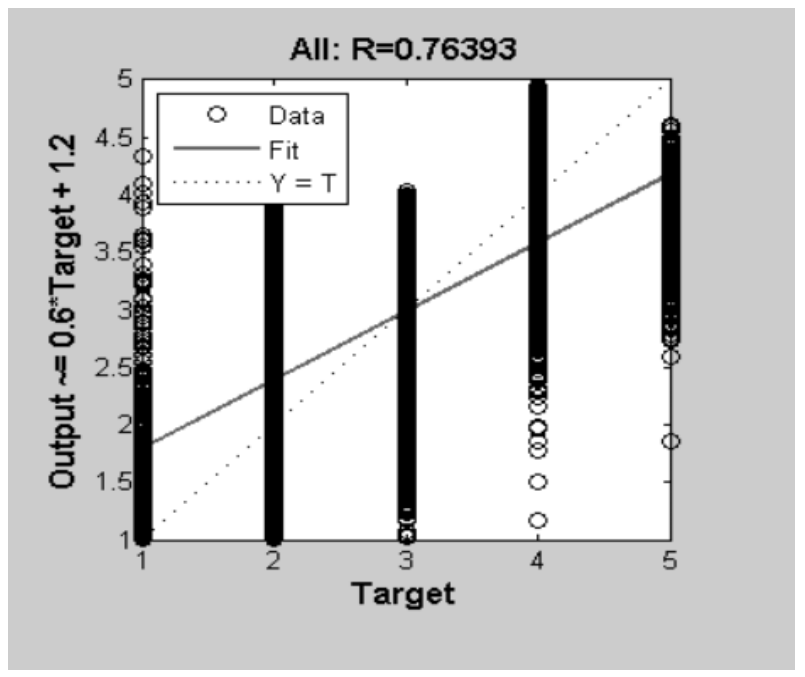

Şekil 10. YSA'nın tahmin grafiği 


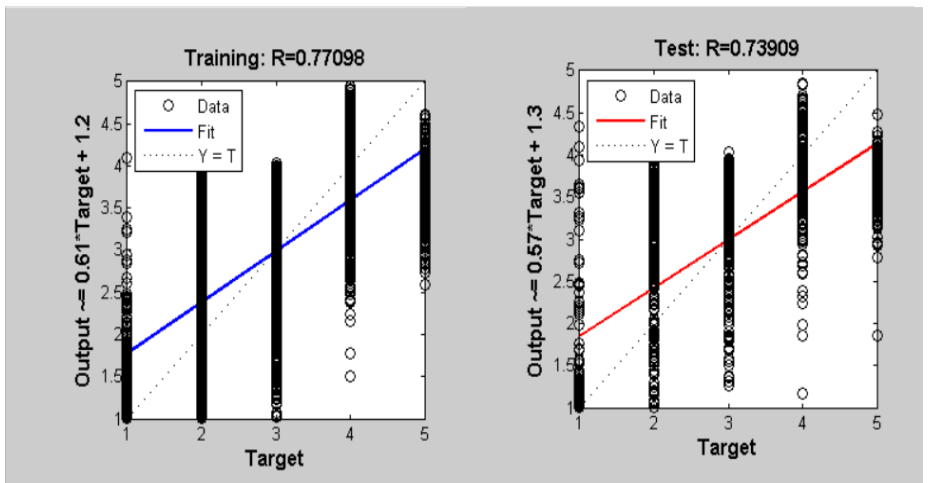

Şekil 11. YSA'nın eğitim ve test grafikleri

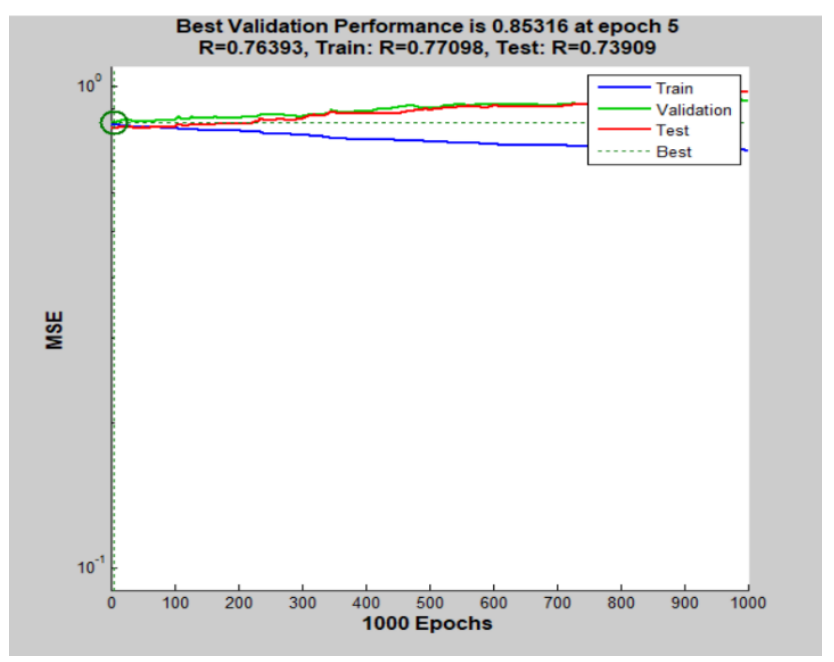

Şekil 12. Ortalama hata karesi grafiği

\subsection{LDA Bulguları}

Çalışmada hem LDA için hem de K-NN sınıflandırması için $\mathrm{k}$-fold cross validation yöntemi vasıtasıyla veriler eşit büyüklükte $\mathrm{k}$ tane bölüme ayrılmıştır. Uygulamada $\mathrm{k}=5$ olduğu durumda sınıflayıcılar üzerinde daha iyi başarım elde ettiği tespit edilmiştir. $\mathrm{K}$-fold cross validation işlemi ile birlikte $\mathrm{k}$ değeri kadar yani uygulamada $5 \mathrm{kez}$ veri kümesi sınıflandırılmış, veri 5 tane gruba ayrılmıştır. . Bu gruplardan her defasında veri kümesinin bir tanesi test seti olarak kullanılırken geriye kalan diğer dört tanesi eğitim seti olarak kullanılmıştır.

\begin{tabular}{|c|c|c|c|c|}
\hline Veri Kümesi \\
\hline Test & Eğitim & Eğitim & Eğitim & Eğitim \\
\hline Eğitim & Test & Eğitim & Eğitim & Eğitim \\
\hline Eğitim & Eğitim & Test & Eğitim & Eğitim \\
\hline Eğitim & Eğitim & Ĕ̈itim & Test & Eğitim \\
\hline Eğitim & Eğitim & Eğitim & Eğitim & Test \\
\hline
\end{tabular}

Şekil 13. K-fold cross validation
Tablo 1. LDA karmaşıklık matrisi

\begin{tabular}{|c|c|c|c|}
\hline \multirow{2}{*}{\multicolumn{2}{|c|}{$\begin{array}{c}\text { LDA } \\
\text { Karmaşıklık Matrisi }\end{array}$}} & \multicolumn{2}{|c|}{ Tahmin } \\
\hline & & Pozitif & Negatif \\
\hline \multirow{2}{*}{ 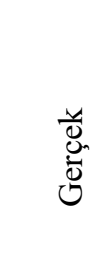 } & Pozitif & $\begin{array}{l}\text { DP (Doğru } \\
\text { Pozitif) } \\
1836\end{array}$ & $\begin{array}{l}\text { YN (Yanlış } \\
\text { Negatif) } \\
4\end{array}$ \\
\hline & Negatif & $\begin{array}{l}\text { YP (Yanlış } \\
\text { Pozitif) } \\
404\end{array}$ & $\begin{array}{l}\text { DN (Doğru } \\
\text { Negatif) } \\
56\end{array}$ \\
\hline
\end{tabular}

LDA sınıflandırıcısından elde edilen karmaşıklık matrisi sonuçları yukarıda gösterilen Tablo 1'de görüldüğü gibidir. Burada k-fold cross validation yöntemine ile test için ayrılmış olan 2300 tane test verisinin karmaşıklık matrisi sonuçlarına göre; DP değeri yani gerçekte epilepsi nöbeti yok olarak kabul edilen verilerin 1836'i sistem tarafından da doğru olarak tahmin edilmiş epilepsi nöbetinin olmadığı şekilde sınıflandırılmıştır. DN değeri yani gerçekte epilepsi nöbeti var kabul edilen verilerin 56's1 sistem tarafından doğru olarak sınıflandırılmış nöbet var şeklinde tahmin edilmiştir. $\mathrm{Bu}$ iki sonuçtan yola çıkılarak doğruluk değerinin \%82 olduğu da doğrulanmıştır. Aynı şekilde YN değeri yani gerçekte epilepsi nöbeti yok olarak kabul edilen verilerin 4'ünü sistem yanlış sınıflandırmış epilepsi nöbeti var olarak tahmin etmiştir. YP değeri için ise gerçekte epilepsi nöbeti var olarak kabul edilen 404 tane verinin sınıflandırmasını sistem yanlış tahmin etmiştir. Bu değerlerden yola çıkılarak duyarlılık değerleri; doğru pozitif oranı 1,00 ve yanlış pozitif oranı 0,87 , kesinlik değeri 0,82 olduğu hesaplanmıştır.

Tablo 2. LDA karmaşıklık matrisi ölçümleri

\begin{tabular}{|c|c|c|c}
\hline class & precision & recall & f1-score \\
\hline $\mathbf{0}$ & 0,82 & 1,00 & 0,90 \\
\hline $\mathbf{1}$ & 0,89 & 0,11 & 0,20 \\
\hline $\begin{array}{c}\text { accuracy } \\
\text { macro avg }\end{array}$ & $\mathbf{0 , 8 2}$ & $\mathbf{0 , 9 9}$ & $\mathbf{0 , 8 2}$ \\
\hline $\begin{array}{c}\text { weighted } \\
\text { avg }\end{array}$ & 0,86 & 0,55 & 0,55 \\
\hline
\end{tabular}

Tablo 2'de de görüldüğü gibi hesaplanan değerlerle paralellikte kesinlik, duyarlılık ve F-ölçütü değerleri sistemden çıktı olarak doğru şekilde alınmıştır. 2300 tane test verisinin tamamında test yapılmış bu verinin 1836 tanesi 0 sınıfına ait olarak doğru sınıflandırılmıştır. Fakat LDA algoritmasında 1 sınıfı için yani nöbet geçiren hastalardan alınan verilerde sistemin daha fazla hata yaptığı sadece 56 tanesinin doğru sınıflandırıldığ görülmüştür. $\mathrm{Bu}$ durumun sistem çıktısında da doğrulandığı 1 sınıfına ait duyarlılık değerinin 0,11 çıkması ile tespit edilmiştir. 


\subsection{K-NN Bulguları}

Tablo 3. K-NN parametreleri

\begin{tabular}{|c|c|c|}
\hline Uzaklık & k komşu sayısı & Başarı Oranı \\
\hline \multirow{3}{*}{ "minkowski" } & $k=3$ & $\% 93,41$ \\
\hline & $k=5$ & $\% 92,56$ \\
\hline & $k=7$ & $\% 91,90$ \\
\hline \multirow{3}{*}{ "euclidean" } & $k=3$ & $\% 93,37$ \\
\hline & $k=5$ & $\% 92,47$ \\
\hline & $k=7$ & $\% 91,91$ \\
\hline
\end{tabular}

K-NN sınıflandırıcısı parametreleri seçiminde algoritmada en iyi sonucu veren $\mathrm{k}$ komşu sayısı 3 olarak belirlenirken uzaklık metriği olarak da minkowski seçilmiştir (Tablo 3).

Tablo 4. K-NN karmaşıklık matrisi

\begin{tabular}{|c|c|c|c|}
\hline \multirow{2}{*}{\multicolumn{2}{|c|}{$\begin{array}{c}\text { K-NN } \\
\text { Karmaşıklık Matrisi }\end{array}$}} & \multicolumn{2}{|c|}{ Tahmin } \\
\hline & & Pozitif & Negatif \\
\hline \multirow{2}{*}{ 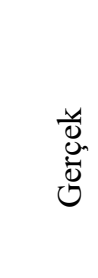 } & Pozitif & $\begin{array}{l}\text { DP (Doğru } \\
\text { Pozitif) } \\
1838\end{array}$ & $\begin{array}{l}\text { YN (Yanlış } \\
\text { Negatif) } \\
2\end{array}$ \\
\hline & Negatif & $\begin{array}{l}\text { YP (Yanlış } \\
\text { Pozitif) } \\
149\end{array}$ & $\begin{array}{c}\text { DN (Doğru } \\
\text { Negatif) } \\
311\end{array}$ \\
\hline
\end{tabular}

K-NN sınıflandırıcısından elde edilen karmaşıklık matrisi sonuçları yukarıda gösterilen Tablo 1'de görüldüğü gibidir. Burada da k-fold cross validation yöntemine göre test için ayrılmış olan 2300 tane test verisinin karmaşıklık matrisi sonuçlarına göre; DP değeri 1838, sistem tarafından doğru olarak tahmin edilmiş epilepsi nöbetinin olmadı $\breve{g ̆}_{1}$ şeklinde sınıflandırılmıştır. DN değeri 311, sistem tarafından doğru olarak sınıflandırılmış nöbet var şeklinde tahmin edilmişstir. Bu iki sonuçtan yola çıkılarak doğruluk değerinin \%93 olduğu da görülmüştür. Aynı şekilde YN değeri yani gerçekte epilepsi nöbeti yok olarak kabul edilen verilerin 2'sini sistem yanlış sınıflandırmış epilepsi nöbeti var olarak tahmin etmiştir. YP değeri için ise edilen 149 tane verinin sınıflandırmasını sistem yanlış tahmin edip nöbeti yok olarak kabul etmiştir. Bu değerlerden yola çıkılarak duyarlılık değerleri; doğru pozitif oranı 1,00 ve yanlış pozitif oranı 0,32 olarak hesaplanmıştır. Ayrıca kesinlik değeri 0,93 olduğu görülmüştür.

Tablo 5'de de görüldüğü gibi hesaplanan değerlerle aynı doğrultuda kesinlik, duyarlılık ve F-ölçütü değerleri sistemden çıktı olarak doğru şekilde alınmıştır. 2300 tane test verisinin tamamında test yapılmış 0 ve 1 sınıfina ait verilerin sınıflandırma başarılarının yüksek çıktığı görülmüştür.
Tablo 5. K-NN karmaşıllık matrisi ölçümleri

\begin{tabular}{|c|c|c|c|}
\hline class & precision & recall & f1-score \\
\hline $\mathbf{0}$ & 0,92 & 1,00 & 0,96 \\
\hline $\mathbf{1}$ & 0,99 & 0,66 & 0,79 \\
\hline accuracy & $\mathbf{0 , 9 3}$ & $\mathbf{0 , 9 9}$ & $\mathbf{0 , 9 3}$ \\
\hline macro avg & 0,96 & 0,83 & 0,88 \\
\hline weighted avg & $\mathbf{0 , 9 4}$ & $\mathbf{0 , 9 3}$ & $\mathbf{0 , 9 3}$ \\
\hline
\end{tabular}

Söz konusu bütün bulgular ele alındığında \%90 üzerinde sonuçlara ulaşmanın gerekli sayıda alternatif algoritma uygulamaları neticesinde mümkün olduğu görülmektedir. $\mathrm{Bu}$ noktada verileri daha detaylı bir biçimde ele alan ve veriler içerisindeki hassas değişimlere karşı daha duyarlı olan derin öğrenme çözümlerinin, bulgularda artış oluşturabileceğini yorumlamak mümkündür. Elbette burada artan başarım bulgularına karşı uygulama sürelerinde artışların da yaşanıp yaşanmayacağ1, yine bu durumun epileptik EEG verisi üzerinden arzu edilen sürelerde sonuçlara ulaşma açısından dezavantaj oluşturup oluşturmayacağı da alternatif bir araştırma sorusu olarak dikkate alınabilecektir.

\section{Sonuç}

Günümüzde biyomedikal verilerden biri olan EEG veri setleri kullanılarak gerek tahminleme gerekse sınıflandırma çalışmaları yapılmakta modeller oluşturulmaktadır. Kullanılabilecek birçok makine öğrenmesi teknikleri bulunmakta veri setine, geliştiricinin tasarımına bağlı olarak bu yöntemler değişkenlik göstermektedir. Bu çalışmada makine öğrenmesinin danışmanlı öğrenme algoritmalarından olan YSA, LDA ve K-NN algoritmaları epileptik EEG verisi üzerinde nöbet tanılama sistemi için denenmiş, performansları kaydedilmiştir. Algoritmaların performanslarının değerlendirilmesi adımında karmaşıklık matrislerinden sonra hesap edilen her bir algoritmanın f ölçütlerine bakılarak yorumlandığında LDA'nın 0 sınıfı için performansı daha iyi iken 1 sınıfı için değerin 1 'den uzaklaştığ1 performansının düştüğü görülmüştür. LDA yönteminin literatürde genel olarak kullanımından farklı olarak literatüre katkı sağlaması adına sınıflandırıcı olarak kullanılması özellikle seçilmiştir. İkili sınıflandırma durumları içeren problemlerde ve veri boyutu büyük olmayan veri setlerinde çalıştırılmasının doğru olduğu kanaatine varılmıştır. K-NN için $\mathrm{f}$ ölçütü değerine göre ise her iki sınıfta da 1'e yakın değerler alındığı algoritmanın başarılı olduğu tespit edilmiştir. Temel YSA tasarımının ortalama hata karesi grafiğine bakıldığındaysa değerin 1'den uzaklaştığı için performansının azaldığ görülmüştür.

Sonuç olarak EEG veri setinde kullanılan üç farklı yaklaşımdan YSA ve LDA algoritmalarına nazaran en iyi sınıflandırıcı olarak çalışan algoritmanın \%93,41 doğruluk oranı ile K-NN olduğu tespit edilmiştir (Tablo 6). 
Tablo 6. Sinıflandırıcıların başarı karşılaştırması

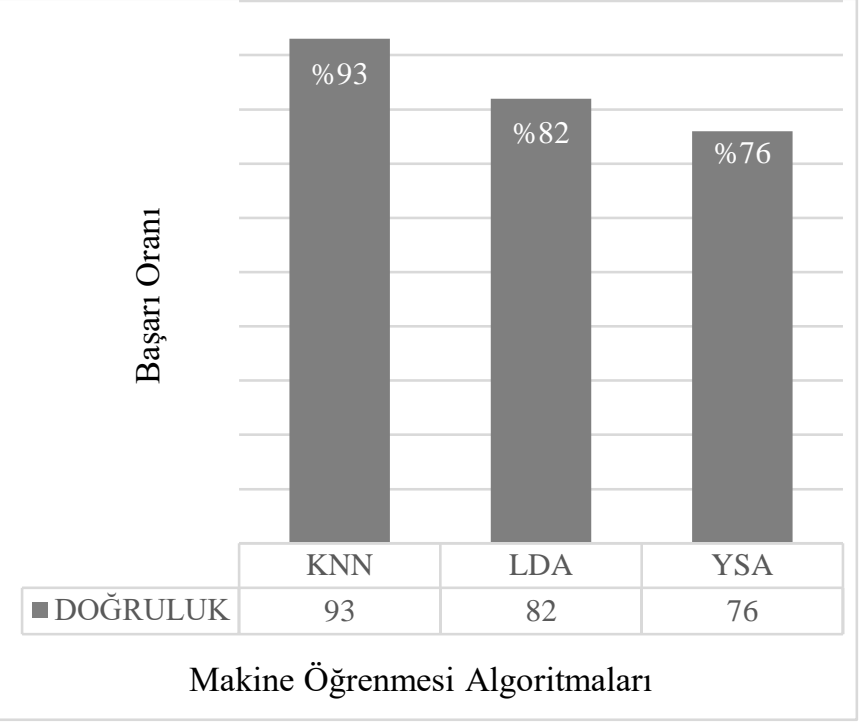

Gelecek çalışmalara öneri olarak MLP gibi daha gelişmiş YSA tasarımları ve özelleştirilmiş bir YSA olan CNN, LSTM gibi derin öğrenme yaklaşımları; çalışmada kullanılan veri seti üzerinde ve farklı EEG veri setleri üzerinde uygulanarak daha farklı sonuçlar elde edilebileceği tahmin edilmektedir. Derin öğrenme algoritmalarının yapılarının karmaşıklığı ve gelişmişliği göz önüne alınarak daha iyi sonuçlara varılabileceği öngörülmekte, gelecek çalışmalarda denenmesi ve böylelikle bir önceki bölüm sonunda ifade edilen başarım-zaman dengesinin ne yönde oluşturulacağının gözlemlenmesinin, bu çalışmada ele alınan araştırma sürecine katkı sağlayacağı düşünülmektedir. Yine alternatif EEG veri setlerinin incelenmesi, karşılaştırmalı süreçlerin çeşitlendirilmesi ve çözümün daha komplike sağlık takibi sistemlere entegrasyonu yönünde çalışmaların da gerçekleştirilebileceği, konuyla ilgilenen araştırmacılara önerilmektedir.

\section{Kaynakça}

Akdağ, G., Algın, D. İ. \& Erdinç, O. O. (2016). Epilepsi. Osmangazi Tıp Dergisi, 38 (Özel Sayı 1), 35-41, Eskişehir.

Alan, M. (2020). Derin Öğrenme İle Biyosinyal Sınıflandırma Ve Hastalık Tahmini (Yüksek Lisans Tezi). Marmara Üniveritesi, Fen Bilimleri Enstitüsü, İstanbul.

Albayrak, M. (2008). EEG Sinyallerindeki Epileptiform Aktivitenin Veri Madenciliği Süreci ile Tespiti (Doktora Tezi). Sakarya Üniversitesi, Fen Bilimleri Enstitüsü, Sakarya.

Alkan, A., Subaşı, A. \& Kıymık, M. (2003). EEG İşaretlerinin Yapay Sinir Ağı ile Sınıflandırmasında En Yüksek Olabilirlik Kestiriminin Kullanılmas1. 11. Sinyal Isleme ve Iletisim Uygulamaları Kurultayı, (s. 741-744). İstanbul.

Andrzejak, R. G., Lehnertz, K., Rieke, C., Mormann, F., David, P., Elger \& C. E. (2001). Indications of Nonlinear Deterministic and Finite Dimensional Structures in Time Series of Brain Electrical Activity: Dependence on Recording Region and Brain State. Pyhsical Review E, 64(6), 1-8.

Asilkan, Ö. \& Irmak, A. G. S. (2009). İkinci El Otomobillerin Gelecekteki Fiyatlarının Yapay Sinir Ağları ile Tahmin Edilmesi. Süleyman Demirel Üniversitesi İktisadi ve İdari Bilimler Fakültesi Dergisi, 4(2), 375-391.

Başçıl, M. S. (2015). Beyinde Üretilen Yöne Bağlı EEG Sinyallerinin Özellik Çıkarımı Yardımıyla Sınıflandırılması
(Doktora Tezi). Sakarya Üniversitesi, Fen Bilimleri Enstitüsü, Sakarya.

Boz, H., \& Köse, U. (2018). Emotion extraction from facial expressions by using artificial intelligence techniques. BRAIN. Broad Research in Artificial Intelligence and Neuroscience, 9(1), 5-16.

Cevizoğlu, H. (2019). Yapay Zekâ, Teknoloji Felsefesi ve Toplumsal Yaşam. Yapay Zekâ ve Gelecek, İstanbul: Doğu Kitabevi.

Copeland, M. (2016). Nvidia, What's the Difference Between Artificial Intelligence, Machine Learning, and Deep Learning? Online Web site: 03.11.2020 tarihinde https://blogs.nvidia.com/blog/2016/07/29/whats-differenceartificial-intelligence-machine-learning-deep-learning-ai/ adresinden erişildi.

Deperlioğlu, Ö. (2018). The Effects of Different Training Algorithms on the Classification of Medical Databases Using Artificial Neural Networks. In European Conference on Science, Art \& Culture ECSAC.

Eşme, E. \& Karlik B. (2014). Comparison Supervised Learning Algorithms for Gases/Odors Identification. Intellectual Systems of Decision-Makıng and Problems of Computatıonal Intelligence (ISDMCI'14). Ukraine.

Gershenson, C. Artificial Neural Networks for Beginners [PDF belgesi]. Lecture Notes Online Web site: 18.01.2021 tarihinde https://www.uv.mx/mia/files/2012/10/Artificial-Neural-

Networks-for-Beginners.pdf adresinden erişildi.

Graupe, D. (2013). Principles of Artificial Neural Networks (3rd edition). World Scientific, Advanced Series in Circuits and Systems: Volume 7, Chicago, University of Illinois, USA. https://doi.org/10.1142/8868

Hasson, U., Nastase, S. A., \& Goldstein, A. (2020). Direct fit to nature: An evolutionary perspective on biological and artificial neural networks. Neuron, 105(3), 416-434.

Haykin, S. (1999). M. Neural Networks - A Comprehensive Foundation (2nd Edition). Prentice Hall, New Jersey.

$\mathrm{Hu}, \mathrm{C}$. (2002). Advanced Tourism Demand Forecasting : ANN and Box-Jenkins Modelling (Doktora Tezi). Purdie University, MI, USA.

Kaya, D. (2019). Alt Uzay k-NN ile Eritmato-Skuamöz Hastalık Türlerinin Sınıflandırılması. Fırat Üniversitesi Mühendislik Bilimleri Dergisi, 31(2), 583-587.

Kaya, D. \& Türk, M. (2017). Biyoelektriksel İşaretlerde Rahatsılılk Teşhisinin Yorumlanması. Fırat Üniversitesi Mühendislik Bilimleri Dergisi, 29(1), 261-267.

Köse, U. (2018a). An Ant-Lion Optimizer-Trained Artificial Neural Network System for Chaotic Electroencephalogram (EEG) Prediction. Applied Sciences, 8(9), 1613. doi:10.3390/app8091613.

Köse, U. (2018b). Are we safe enough in the future of artificial intelligence? A discussion on machine ethics and artificial intelligence safety. BRAIN. Broad Research in Artificial Intelligence and Neuroscience, 9(2), 184-197.

Mitchell, T. (1997). Does Machine Learning Really Work?. AI Magazine, 18(3), USA.

Musumeci, T., Bonaccorso, A., \& Puglisi, G. (2019). Epilepsy Disease and Nose-to-Brain Delivery of Polymeric Nanoparticles: An Overview. Pharmaceutics, 11(3), 118. doi:10.3390/pharmaceutics11030118.

Özcan, A. R. (2020). EEG İşaretlerinde Evrişimli Sinir Ağları ile Epileptik Nöbet Tahmini. (Doktora Tezi). Koceli Üniversitesi, Fen Bilimleri Enstitüsü, Kocaeli. 
Özer, E. (2015). Epilepsi Hastalı̆̆ının Dalgacık Dönüşümleri ve Yapay Sinir Ağları ile Tanılanması (Yüksek Lisans Tezi). Mimar Sinan Güzel Sanatlar Üniversitesi, Fen Bilimleri Enstitüsü, İstanbul.

Öztemel, E. (2012). Yapay Sinir Ağları. İstanbul: Papatya Yayıncılık Eğitim.

Panjeh. M. A. (2018). Bilgisayar Ağlarında Makine Öğrenimi Algoritmalarını Kullanarak İzinsiz Giriş Tespiti (Yüksek Lisans Tezi). Atatürk Üniversitesi, Yönetim Bilişim Sistemleri Anabilim Dalı, Erzurum.

Pehlivan F. (1997). Biyofizik. Ankara: Pelikan Yayınevi.

Polat, H. (2016). Görsel - Isşitsel Uyaranlar Kaynakl Oluşan Duyguların EEG İşaretleri ile Sinıflandırılması (Yüksek Lisans Tezi). Dicle Üniversitesi, Fen Bilimleri Enstitüsü, Diyarbakır.

S.B.Ü. DR. Behçet Uz Çocuk Hatalıkları ve Cerrahisi Eğitim ve Araştırma Hastanesi. (2020). Epilepsi: Çocuk ve Aile Rehberi. Online Web site: 02.10.2020 tarihinde https://behcetuzch.saglik.gov.tr/TR,107628/epilepsi-cocukve-aile-rehberi.html adresinden erişildi.

Sanei, S. \& Chambers, J. A. (2007). EEG Signal Processing. USA: John Wiley \& Sons Ltd. 35-125. https://doi.org/10.1002/9780470511923

Sağıroğlu, Ş., Güney, K. \& Erler, M. (2003). Computatıon of Radiation Efficiency For A Resonant Rectangular Microstrip Patch Antenna Using Backpropagation Multilayered Perceptrons, Istanbul University Journal of Electrical \& Electronics Engineering, 3(1), 663-671.

Şenol, C. (2006). EEG Sinyallerinin Zaman Serileri ile Modellenmesi (Yüksek Lisans Tezi). Ankara Üniversitesi, Fen Bilimleri Enstitüsü, Ankara.

Taşçı, A. E. \& Onan, A. (2016). K En Yakın Komşu Algoritması Parametrelerinin Sinıflandırma Performans1 Üzerine Etkisinin İncelenmesi. Akademik Bilişim, (s. 1-8). Aydın.

Taywade, S. A. \& Raut, R. D. (2012). A Review: EEG Signal Analysis with Different Methodologies. IJCA Proceedings on National Conference on Innovative Paradigms in Engineering and Technology (NCIPET 2012), ncipet(6)2931, March 2012. https://www.ijcaonline.org/proceedings/ncipet/number6/523 6-1048

Tekin, R., Kaya, Y. \& Tağluk, M. E. (2011). K-means ve YSA temelli Hibrit Bir Model ile Epileptik EEG İşaretlerinin Sinıflandırılması. Elektrik- Elektronik ve Bilgisayar Seтроzyuтu, (s. 277-283). Elazığ: TMMOB Elektrik Mühendisleri Odası.

Varsavsky, A., Mareels, I. \& Cook, M. (2016). Epileptic Seizures and the EEG: Measurement, Models, Detection and Prediction, 1st ed., CRC Press, USA.

World Health Organization. (2020). World Health Organization: Epilepsy. Online Web site: 2.09.2020 tarihinde https://www.who.int/news-room/fact-sheets/detail/epilepsy adresinden erişildi.

Yegnanarayana, B. (2009). Artificial Neural Networks. PHI Learning Pvt. Ltd..

Yeditepe. (2019). Yeditepe Epilepsisiz. Online Web site: 20.09.2019 tarihinde http://www.yeditepeepilepsisiz.com/epilepsi/ $\quad$ adresinden erişildi.

Zupec-Kania B.A. \& Spellman E. (2009). An Overview of The Ketogenic Diet for Pediatric Epilepsy, Nutrition in Clinical Practice, 23(6), 589-596. doi: 10.1177/0884533608326138. PMID: 19033218. 